\title{
Acute Myocarditis After Black Widow Spider Bite: A Case Report
}

\author{
A. Piscopo - F. Massari - P. Scicchitano (D) - M. Sanasi • \\ M. De Palo · P. Caldarola · M. Liccese - G. Calculli
}

Received: April 27, 2020 / Published online: May 27, 2020

(C) The Author(s) 2020

\section{ABSTRACT}

The black widow spider (BWS) is a venomous spider whose bite can cause various clinical conditions that range from local damage to serious systemic complications, including death. Cases of myocarditis following a BWS bite are rare but they can be fatal on occasion. However, the prognostic significance of the bite and presentation of myocarditis is unknown. Our case involved a 50-year-old man who presented with myocarditis after being bitten by a BWS and subsequently admitted to the intensive care unit for cardiac monitoring. During

Digital Features To view digital features for this article go to https://doi.org/10.6084/m9.figshare.12292886.

A. Piscopo - F. Massari - P. Scicchitano ( $₫)$.

M. Sanasi

Cardiology Unit, Hospital "F. Perinei”, Bari Local

Health Authority (ASL Bari), Altamura, Bari, BA, Italy

e-mail: piero.sc@hotmail.it; pietrosc.83@libero.it

M. De Palo

Cardiac Surgery Department, University of Bari,

Bari, BA, Italy

P. Caldarola

Cardiology Unit, Hospital "San Paolo, Bari Local

Health Authority (ASL Bari), Bari, BA, Italy

M. Liccese - G. Calculli

Cardiology Unit, Hospital "Madonna Delle Grazie",

Matera Local Health Authority (ASL Matera),

Matera, MT, Italy

the hospital stay, he showed worsening signs on both the electrocardiographic and echocardiographic evaluations despite therapeutic success. Subsequent cardiac magnetic resonance and coronary angiography investigations showed no significant alterations; blood and instrumental test results slowly improved, and the patient was discharged home after 12 days of hospitalization without complications. This case illustrates that acute myocarditis, although an infrequent complication of BWS bite, has the potential to be lethal. The correct diagnosis, which is not always easy to formulate, is important to identify those patients who can benefit from careful monitoring and specific therapies aimed at reducing the risk of life.

Keywords: Black widow; Heart attack; Myocarditis; Spider 


\section{Key Summary Points}

Envenomation from spiders can cause serious adverse events.

We observed a case of myocarditis in a person bitten by a black widow spider.

Rapid admission to the ward and the empirical treatments were fundamental to therapeutic success.

Myocarditis from spider bites should be considered as possible adverse effects although they are rare events.

\section{INTRODUCTION}

Latrodectus tredecimguttatus, more commonly known as the Mediterranean black widow spider, is a 12 - to 15 -mm-large spider with several red, hourglass-shaped marks on its abdomen $[1,2]$. Its bite releases a neurotoxic alpha-latrotoxin that binds to the pre-synaptic neuronal receptor neurexin, inserts itself into the neuronal membrane, and creates a transmembrane calcium channel that mediates exocytosis of noradrenaline/acetylcholine and sodium channels opening at both neuromuscular junction and post-ganglionic noradrenergic synapses [3].

Patients may experience edema, necrosis, and bacterial superinfection at the inoculum site. The toxin can distally affect nerves, muscles, and organs (i.e., bladder, lungs, and heart) $[4,5]$. Systemic symptoms and signs develop in approximately one third of patients who have been bitten, and rare cases of myocarditis have been reported [6].

The patient described in this case report provided written informed consent to publish data and clinical details relating to his condition and treatment.

\section{CASE PRESENTATION}

A healthy 50-year-old man experienced black widow spider (BWS) envenomation. After the bite, he manifested sweating, wrist paraesthesia, and pain at the initial bite site with inoculum spreading to the upper arms. Laboratory tests revealed leukocytosis and increased plasma levels of C-reactive protein, cardiac troponin-I, and brain natriuretic peptide (Table 1). Arterial blood gas analysis, chest X-rays, and echocardiographic examinations were normal at admission; electrocardiogram (ECG) showed diphasic $\mathrm{T}$ waves in lateral leads (Fig. 1a) which were not present in previous outpatient ECGs.

Due to the lack of available antidotes, the patient was empirically treated with intravenous fluids for hydration, analgesics for the relief of pain, benzodiazepines for agitation, antibiotics to prevent infection, steroids, and anti-histamines for periorbital edema. On day 1 of hospitalization, the ECG showed negative $\mathrm{T}$ waves in lateral and inferior leads (Fig. 1b), abnormalities in the wall motion of the left ventricle (LV) in association with moderate systolic dysfunction (hypokinesia of the LV middle/basal segments of the inferior, lateral and inferior-lateral walls); and LV ejection fraction (LVEF) of $48 \%$. The decrease in LVEF was confirmed by speckle tracking analysis: global longitudinal strain (GLS) showed a reduced LV contractile performance $(-14 \%)$. Angiotensin-converting enzyme inhibitors, beta-blockers, and diuretics were administered. Cardiac magnetic resonance (CMR) was carried out on day 6 to confirm the diagnosis of myocarditis, with the results showing an LVEF of $51 \%$ and no signs of myocardial edema/diffuse fibrosis. A minimal area of focal fibrosis was detected at the junction between the left atrium and ventricle, although this finding was not specific (Fig. 2). Coronary angiography excluded coronary stenosis (Fig. 3).

On day 11, the echocardiographic findings (LVEF 55\%, GLS - 19\%) and cardiac enzymes were normal and the patient was discharged with medical therapy for heart failure. 
Table 1 Main laboratory test values of the patient during his hospital stay

\begin{tabular}{|c|c|c|c|c|}
\hline \multirow[t]{2}{*}{ Laboratory Characteristics of the Patient } & \multirow[t]{2}{*}{ Normal range } & \multicolumn{3}{|c|}{$\begin{array}{l}\text { Laboratory test values for the patient during } \\
\text { hospitalization }\end{array}$} \\
\hline & & First day & Second day & Third day \\
\hline \multicolumn{5}{|l|}{ Complete blood count } \\
\hline White blood cell $\left(/ \mathrm{mm}^{3}\right)$ & $4.3-10 \times 10^{3}$ & $11.4 \times 10^{3}$ & $13.3 \times 10^{3}$ & $14.3 \times 10^{3}$ \\
\hline Red blood cells $\left(/ \mathrm{mm}^{3}\right)$ & $3.9-5.2^{*} 10^{6}$ & $4.89 \times 10^{6}$ & $5.36 \times 10^{6}$ & $5.45 \times 10^{6}$ \\
\hline Hemoglobin (g/dL) & $12-16$ & 14.3 & 15.5 & 16.6 \\
\hline Platelets $\left(/ \mathrm{mm}^{3}\right)$ & $140-159 \times 10^{3}$ & $304 \times 10^{3}$ & $285 \times 10^{3}$ & $248 \times 10^{3}$ \\
\hline \multicolumn{5}{|l|}{ Renal function } \\
\hline Blood urea nitrogen $(\mathrm{mg} / \mathrm{dL})$ & $17-50$ & 34 & 26 & 33 \\
\hline Creatinine $(\mathrm{mg} / \mathrm{dL})$ & $0.51-1.17$ & 0.98 & 0.66 & 0.77 \\
\hline $\mathrm{eGFR}\left(\mathrm{mL} / \mathrm{min} / 1.73 \mathrm{~m}^{2}\right)$ & $>60$ & 90 & 113 & 106 \\
\hline \multicolumn{5}{|l|}{ Electrolytes } \\
\hline Sodium $(\mathrm{mEq} / \mathrm{L})$ & $136-146$ & 142 & 138 & 137 \\
\hline Potassium $(\mathrm{mEq} / \mathrm{L})$ & $3.5-5.1$ & 3.9 & 4.0 & 4.2 \\
\hline Chlorine $(\mathrm{mEq} / \mathrm{L})$ & $101-109$ & 99 & 98 & 95 \\
\hline Calcium $(\mathrm{mg} / \mathrm{dL})$ & $8-10.6$ & 9.5 & 9.9 & 10.4 \\
\hline \multicolumn{5}{|l|}{ Cardiac enzymes and inflammatory markers } \\
\hline Troponin I-high sensitivity (ng/L) & $<25$ & 2.4 & 1581.5 & 4323.2 \\
\hline Brain natriuretic peptide $(\mathrm{pg} / \mathrm{mL})$ & $145-250$ & 1332 & 1995 & - \\
\hline C-reactive protein $(\mathrm{mg} / \mathrm{L})$ & $0-5$ & 73.56 & - & - \\
\hline \multicolumn{5}{|l|}{ Coagulation } \\
\hline D-dimer $(\mathrm{ng} / \mathrm{mL})$ & $50-500$ & 412 & 345 & - \\
\hline
\end{tabular}

$-e G F R$ Estimated glomerular filtration rate

\section{DISCUSSION}

Myocarditis is an inflammatory disease of the myocardium that is diagnosed on the basis of established histological, immunological, and immunohistochemical criteria [7]. Although the specific pathogenesis of myocarditis after a spider bite remains uncertain, possible mechanisms are the direct toxic effect of alpha-latrotoxin, excessive noradrenaline/acetylcholine release, and immunological mechanisms (i.e., allergy or hypersensitivity reactions) [7].

Our case report is an interesting example of a rare myocarditis form. Diagnosis was challenging and was mainly based on a few clinical signs, results from diagnostic tools (ECG, CMR), and laboratory values, which ultimately revealed the hidden cause of patient's illness.

Physicians have several instruments at their disposial for diagnosing myocarditis. Endomyocardial biopsy (EMB) is considered the gold standard for diagnosis, but focal dissemination of the pathogens, rare right ventricle involvement, and immune-mediated forms with little/ no cellular infiltrate strongly limit EMB in terms of performance [8]. In one study, only $30 \%$ of post-mortem-proven myocarditis met the 


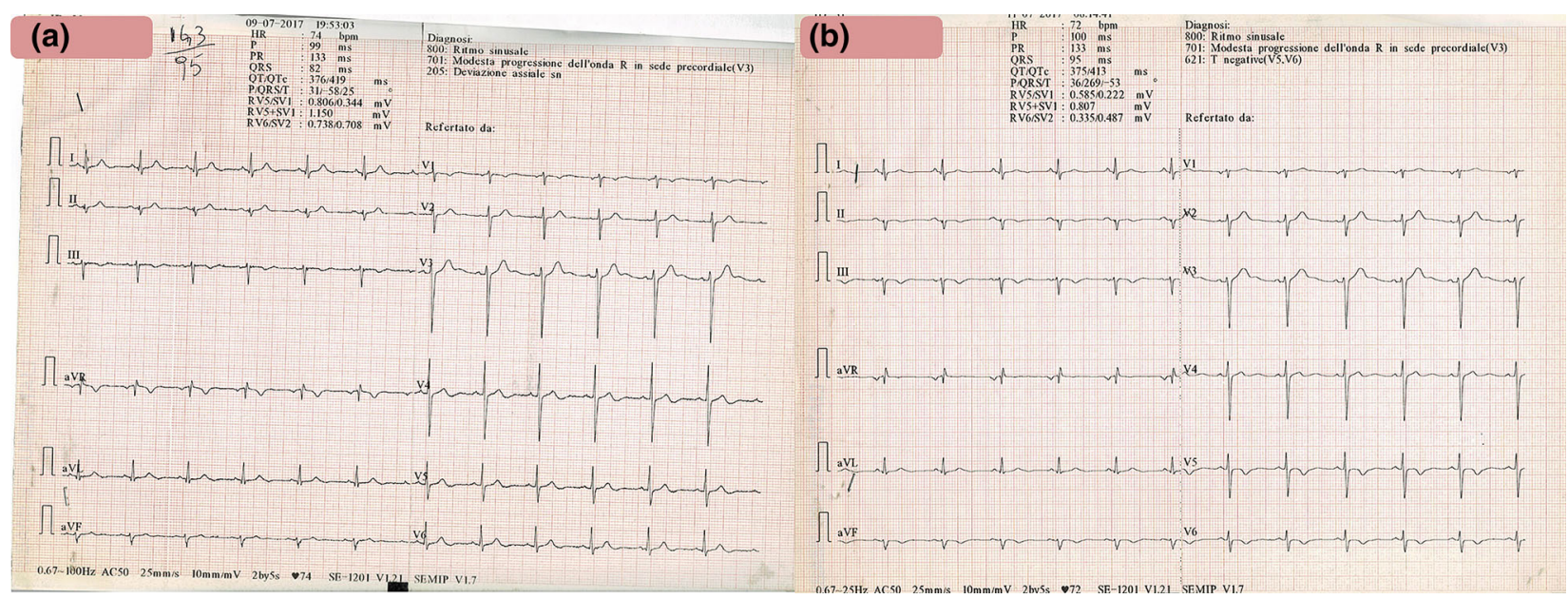

Fig. 1 Variations in electrocardiogram (ECG) of patient during hospital stay. a ECG at admission showing sinus rhythm and diphasic $T$ waves in lateral leads, $\mathbf{b}$ ECG on third day after admission showing sinus rhythm and negative $\mathrm{T}$ waves in lateral and inferior leads

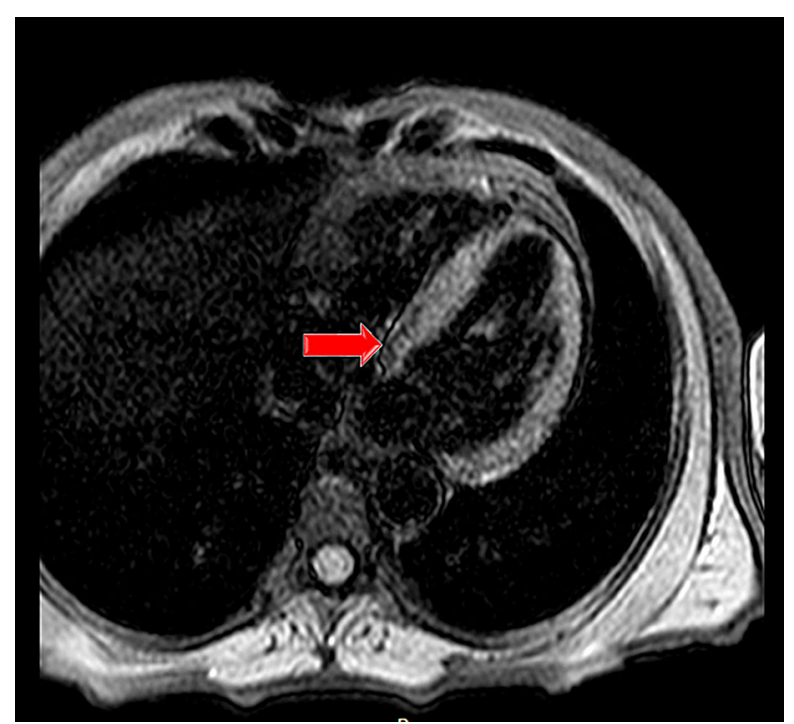

Fig. 2 Cardiac magnetic resonance imaging showed no sign of myocardial edema or diffuse fibrosis. A minimal area of focal fibrosis could be seen at the junction between the left atrium and ventricle

Dallas criteria [7]. EMB is not sensitive, has a relatively high false negative rate, is expensive, and requires expertise to perform. Current guidelines promote its use only in patients with acute, unexplained heart failure with hemodynamic instability [9]. Our patient was hemodynamically stable and did not meet any of the criteria for being transferred to an EBM-performing center.

CMR is accurate in describing ventricular morphology and functions well in characterizing cardiac tissue. CMR has a diagnostic accuracy for myocarditis of close to $80 \%$ and a negative predictive value of $70 \%$ [10]; T1- and T2-weighted images in addition to late gadolinium enhancement (LGE) improve the final diagnosis [11-13]. Nevertheless, CMR also has limitations: minimal variations can not be detected; borderline myocarditis or cytokine/ humoral-mediated forms might not induce injuries to myocytes, thus no LGE can be seen; finally, the time from symptom onset to CMR performance may influence the results. Therefore, some patients with clinical myocarditis may show normal findings on CMR images [14]. Our case illustrates the limitations of CMR to diagnose myocarditis: despite the signs and the symptoms of the patient clearly being related to a myocarditis condition, no overt features of myocarditis were demonstrated with CMR mapping.

Echocardiography ameliorates the diagnosis of myocarditis. Some findings include: LV dilatation and thickness (edema), systolic/diastolic dysfunction, regional wall motion abnormalities, pericardial effusion, and changes in myocardial texture [15]. Echocardiography is the first approach in acute myocarditis due to its 


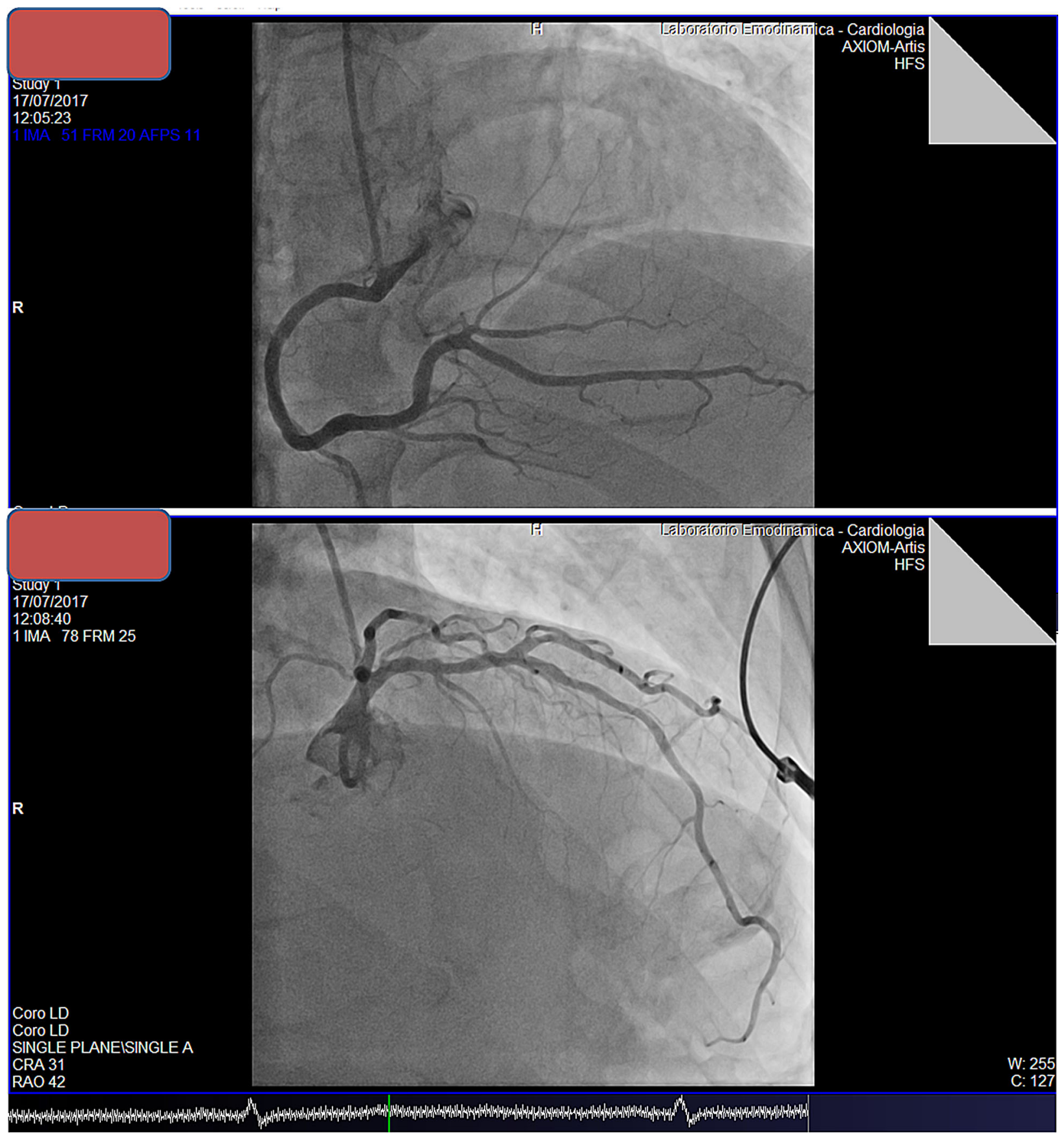

Fig. 3 Coronary angiography

non-invasiveness and good performance in follow-up [16]. Nevertheless, no specific echocardiographic features have been recognized in acute myocarditis, especially in patients with preserved LV systolic function. Initially our patient showed no alteration in LVEF; later, the reduction in GLS value associated with the natural course of the disease suggested the negative influence of inflammation on the myocardium [17]. 


\section{CONCLUSION}

A BWS bite rarely causes acute myocarditis. Confirmation of a diagnosis of myocarditis is difficult and based on a comprehensive cardiac evaluation that includes biomarkers (i.e., troponin or natriuretic peptides) and instrumental assessment (i.e., echocardiography, CMR, and coronary angiography). Further studies are needed to improve the diagnosis of myocarditis.

\section{ACKNOWLEDGEMENTS}

We thank the participant of the study.

Funding. No funding or sponsorship was received for this study or publication of this article.

Authorship. All named authors meet the International Committee of Medical Journal Editors (ICMJE) criteria for authorship for this article, take responsibility for the integrity of the work as a whole, and have given their approval for this version to be published. All named authors meet the International Committee of Medical Journal Editors (ICMJE) criteria for authorship for this article, take responsibility for the integrity of the work as a whole, and have given their approval for this version to be published.

Prior Presentation. This case was previously presented as a poster at the 50th Congress of the Italian Association of Hospital Cardiologists (ANMCO) Rimini (Italy), 16-18 May 2019 and at the 80th Italian Society of Cardiology (SIC) National Congress 2019, Rome (Italy), 12-15 December 2019.

Disclosures. Assunta Piscopo, Francesco Massari, Pietro Scicchitano, Mariella Sanasi, Micaela De Pal, Pasquale Caldarola, Mariarosa Liccese and Giacinto Calculli have nothing to disclose.

Compliance with Ethics Guidelines. The patient described in this case report provided written informed consent to publish data and clinical details relating to his condition and treatment.

Data Availability. The datasets during and/ or analyzed during the current study are available from the corresponding author on reasonable request.

Open Access. This article is licensed under a Creative Commons Attribution-NonCommercial 4.0 International License, which permits any non-commercial use, sharing, adaptation, distribution and reproduction in any medium or format, as long as you give appropriate credit to the original author(s) and the source, provide a link to the Creative Commons licence, and indicate if changes were made. The images or other third party material in this article are included in the article's Creative Commons licence, unless indicated otherwise in a credit line to the material. If material is not included in the article's Creative Commons licence and your intended use is not permitted by statutory regulation or exceeds the permitted use, you will need to obtain permission directly from the copyright holder. To view a copy of this licence, visit http:// creativecommons.org/licenses/by-nc/4.0/.

\section{REFERENCES}

1. Isbister GK, Fan HW. Spider bite. Lancet. 2011;378: 2039-47.

2. Boyer LV, Binford GJ, Degan JA. Spider bites. In: Auerbach PS, editor. Wilderness medicine. 6th edition. Philadelphia: Elsevier Mosby; 2012. p. 975-95.

3. Orlova EV, Rahman MA, Gowen B, et al. Structure of alpha-latrotoxin oligomers reveals that divalent cation dependent tetramers form membrane pores. Nat Struct Biol. 2000;7:48-53.

4. Isbister GK. Spider bite: a current approach to management. Aust Prescr. 2006;2013:156-8.

5. Kara H, Ahmet AK, Bayr A, Avci A. Reversible myocarditis after spider bite. BMJ Case Rep. 2013. https://doi.org/10.1136/bcr-2013-008957. 
6. Yaman M, Mete T, Ozer I, Yaman E, Beton O. Reversible myocarditis and pericarditis after black widow spider bite or Kounis syndrome? Case Rep Cardiol. 2015;2015:768089.

7. Caforio AL, Pankuweit S, Arbustini E, et al. Current state of knowledge on aetiology, diagnosis, management and therapy of myocarditis: a position statement of the European Society of Cardiology Working Group on myocardial and pericardial disease. Eur Heart J. 2013;34:2636-48.

8. Mahrholdt H, Goedecke C, Wagner A, et al. Cardiovascular magnetic resonance assessment of human myocarditis: a comparison to histhology and molecular pathology. Circulation. 2004;109: $1250-8$.

9. Cooper LT, Baughman KL, Feldman AM, et al. The role of endomyocardial biopsy in the management of cardiovascular disease: a scientific statement from the America Heart Association, the American College of Cardiology, and the European Society of Cardiology. Endorsed by the Heart Failure Society of America and the Heart Failure Association of the European Society of Cardiology. J Am Coll Cardiol. 2007;50:1914-31.

10. Lagan J, Schmitt M, Miller CA. Clinical applications of multi-parametric CMR in myocarditis and systemic inflammatory diseases. Int $\mathrm{J}$ Cardiovasc Imaging. 2018;34:35-54.

11. Kotanidis CP, Bazmpani MA, Haidich AB, Karvounis C, Antoniades C, Karamitsos TD. Diagnostic accuracy of cardiovascular magnetic resonance in acute myocarditis: a systematic review and meta-analysis. JACC Cardiovasc Imaging. 2018;11:1583-90.

12. Friedrich MG, Sechtem U, Schulz-Menger J, et al. Cardiovascular magnetic resonance in myocarditis: a JACC white paper. J Am Coll Cardiol. 2009;53: 1475-87.

13. Baccouche $H$, Mahrholdt $H$, Meinhardt $G$, et al. Diagnostic synergy of non-invasive cardiovascular magnetic resonance and invasive endomiocardial biopsy in troponin positive patients without coronary artery disease. Eur Heart J. 2009;30:2869-79.

14. Abdel-Aty H, Boyé P, Zagrosek A, et al. Diagnostic performance of cardiovascular magnetic resonance in patients with suspected acute myocarditis: comparison of different approaches. J Am Coll Cardiol. 2005; 7:1815-22.

15. Skouri NH, Dec GW, Friedrich MG, Cooper LT. Noninvasive imaging in myocarditis. J Am Coll Cardiol. 2006;48:2085-93.

16. Ammirati E, Cipriani M, Lilliu M, et al. Survival and left ventricular function changes in fulminant versus non fulminant acute myocarditis. Circulation. 2017;136:529-45.

17. Kostakou PM, Kostopoulos VS, Tryfou ES, et al. Subclinical left ventriculat dysfunction and correlation with regional strain analysis in myocarditis with normal ejection fraction A new diagnostic criterion. Int J Cardiol. 2018;259:116-21. 